\title{
Avaliação no Bloco Inicial de Alfabetização no Distrito Federal
}

\author{
BENIGNA MARIA DE FREITAS VILLAS BOAS \\ Professora da Faculdade de Educação da Universidade de Brasília \\ mbboas@terra.com.br
}

\begin{abstract}
Resumo
O texto apresenta resultados de uma pesquisa sobre as práticas avaliativas no Bloco Inicial de Alfabetização - BIA no Distrito Federal (DF). Esse bloco foi implantado em 2005 em 52 escolas de Ceilândia, cidade do DF. As informações foram coletadas por meio de: entrevistas com coordenadoras pedagógicas que atuam na Secretaria de Estado de Educação do DF e na Diretoria Regional de Ensino de Ceilândia; análise do documento orientador do BIA; análise de 33 projetos interventivos de escolas de Ceilândia e de informações obtidas por questionário respondido por professores. $\mathrm{O}$ texto compõe-se de análise do pioneirismo do DF na implantação de fases e etapas, no início da década de 60; do trabalho coletivo dos professores e do projeto interventivo, aspectos destacados no documento orientador do BIA; e dos aspectos relacionados à avaliação, apontados pelo documento orientador. Conclui-se com a apresentação de desafios para a avaliação, impostos pela implantação de bloco de alfabetização.

Palavras-chave: avaliação, Bloco Inicial de Alfabetização, trabalho pedagógico.
\end{abstract}

\section{Resumen}

Este escrito presenta resultados parciales de una investigación acerca de la evaluación en el Ciclo Inicial de Alfabetización en el Distrito Federal. Este Ciclo fue implantado en 2005 en 52 escuelas de Ceilândia, ciudad del Distrito Federal. Los datos fueron obtenidos por intermedio de: entrevistas con supervisores que trabajan en la Secretaria de Estado de Educación del Distrito Federal y en la Directoria Regional de Enseñanza de Ceilândia; análisis de 33 proyectos intervenidos de escuelas de Ceilândia; análisis de informaciones obtenidas por intermedio de cuestionario respondido por profesores. Este escrito discurre sobre: el facto del Distrito Federal tener sido lo primero a implantar ciclos en Brasil, en forma de fases y etapas, en el inicio dos años 1960; el trabajo colectivo de profesores y el proyecto intervencionista, aspectos destacados en el documento orientador del Ciclo Inicial de Alfabetización; y los aspectos relacionados a la evaluación. Al final del escrito se presentan desafios para la evaluación en virtud de la implantación del Ciclo Inicial de Alfabetización.

Palabras-clave: evaluación, Ciclo Inicial da Alfabetización, trabajo pedagógico.

\begin{abstract}
This article discusses the partial results of a research on assessment in the Initial Cycle of Literacy in the Federal District. This cycle began in 2005 at 52 schools in Ceilândia, one of the Federal District's cities. Data were collected through: interviews with supervisors who worked in the Federal District's State Secretary of Education and others who worked in Ceilândia; an analysis of the document that guides the Initial Cycle of Literacy; an analysis
\end{abstract}


of 33 interventional projects formulated by the schools; an analysis of the information elicited from a questionnaire answered by school teachers. This article deals with: the Federal District's innovative endeavor in the implementation of phases and steps, instead of grades, when education was first established in Brasilia, in 1960, the year of its inauguration; the teachers' collaborative work and the interventional projects, aspects that are emphasized in the official guidelines; and aspects related to assessment in the official guidelines. The data highlights the challenges for assessment in the Initial Cycle of Literacy.

Key words: assessment, Initial Cycle of Literacy, pedagogical work. 
A organização da escolaridade em ciclos surgiu na década de 60, no Brasil. Elevados índices de reprovação e repetência, principalmente nos anos iniciais do ensino fundamental, motivaram a sua implantação, em substituição ao regime seriado. Algumas das experiências pioneiras de adoção de ciclos foram a do Distrito Federal (Fases e Etapas, de 1960, quando Brasília foi inaugurada, até o final da década de 60), a de São Paulo (Organização por Níveis, de 1968 a 1972); a de Santa Catarina (Sistema de Avanços Progressivos, de 1970 a 1984); e a do Rio de Janeiro (Bloco Único de Alfabetização, de 1979 a 1984). A implantação de ciclos no Brasil sempre esteve vinculada à necessidade de eliminar o fracasso escolar, estreitamente relacionado às práticas avaliativas. Não se pode responsabilizar inteiramente a avaliação por esse fracasso, mas, também, não se pode isentá-la. A avaliação é central no trabalho com ciclos: espera-se que a sua função tradicional de aprovar e reprovar e de atribuir notas seja substituída pela que promova a aprendizagem de alunos e professores e o desenvolvimento da escola. Com esta última função, a avaliação acompanha todo o processo e reorganiza o trabalho pedagógico. Mais uma vez, a Secretaria de Estado de Educação do Distrito Federal inicia a organização da escolaridade em ciclos. Dentre as medidas para incorporação das crianças de 6 anos de idade ao ensino fundamental, foi implantado, em 2005, em 52 escolas de Ceilândia (uma das cidades do DF), o Bloco Inicial de Alfabetização - BIA. Este texto apresenta resultados da pesquisa realizada em 2005 sobre as práticas avaliativas adotadas pelo BIA. Analisam-se as orientações gerais para a implantação do BIA, no DF, referentes à avaliação; comentam-se dois componentes que se destacam no documento orientador: o trabalho coletivo dos professores e a construção do projeto interventivo pelas escolas; por fim, apontam-se alguns dos desafios postos para a avaliação.

As informações foram coletadas por meio de: entrevistas com coordenadoras pedagógicas que atuavam na Secretaria de Estado de Educação do DF e na Diretoria Regional de Ensino de Ceilândia; análise do documento Orientações Gerais para o Ensino Fundamental de 9 anos: Bloco Inicial de Alfabetização; análise de 33 projetos interventivos de escolas de Ceilândia; e análise de questionário respondido por professores.

\section{PIONEIRISMO DO DF: IMPLANTAÇÃO DE FASES E ETAPAS NA DÉCADA DE 60}

Na década de 60, quando foi implantada a educação pública no DF, o ensino primário apresentava alto índice de reprovação da primeira para a 
segunda série. Para combater esse problema, o ensino nesse nível foi organizado em fases e etapas. A Indicação $n^{\circ} 5$, do Conselho de Educação do DF, aprovada em 21/05/63 (Brasília, 1966), que traça normas preliminares para a organização do sistema de ensino no Distrito Federal, quanto à educação de grau primário, estabelece em seu Título I, Capítulo I, artigo $1^{\circ}$ :

O curso primário é dividido em três fases. A primeira fase abrange a primeira e a segunda séries; a segunda fase abrange a terceira, a quarta e a quinta séries; a terceira fase abrange a classe complementar de sexta série que pode funcionar nas escolas do Plano Pilôto (sic!) e das cidades satélites.

Uma publicação da Coordenação de Educação Primária (Brasília, 1969) apresenta a justificativa para a criação das fases, as quais corresponderiam ao que hoje se denominam ciclos:

Como é constante nos sistemas brasileiros, o ensino primário, em Brasília, apresentava maior e acentuada concentração de alunos na chamada, tradicionalmente, primeira série (iniciação do curso primário fundamental). Observa-se, ainda, o mais expressivo estrangulamento na passagem desta $1^{a}$ série para a $2^{a}$ - aí, o registro de maior índice de reprovações. A Indicação $n^{o} 5$ do Conselho de Educação do DF estabeleceu as normas para organização $e$ funcionamento do sistema de ensino primário. E considera que êste (sic!) ensino deverá compreender duas fases: a primeira corresponde à $1^{a}$ e $2^{a}$ séries primárias e a segunda corresponde à $3^{a}, 4^{a}$ e $5^{a}$ séries. (p. 4)

(...) Definimos, assim, a primeira fase (dois primeiros anos de escolaridade) como fase de alfabetização, compreendendo quatro etapas principais a serem vencidas pelo aluno em dois anos letivos: a $1^{a}$ etapa corresponde ao estudo do pré-livro; a $2^{a}$ ao livro de leitura intermediária, a $3^{a}$ ao primeiro livro e a $4^{a}$ ao do segundo livro. Embora admitamos que a média dos alunos possa vencer cada etapa em 6 (seis) meses, muitos alunos conseguem vencê-la em muito menos tempo e outros precisarão de mais tempo, o que poderá estender a primeira fase a 2 anos e meio ou até 3 anos. A perspectiva de mais de 3 anos na primeira fase determinará exames clínicos e psicológicos do aluno e, se fôr (sic!) o caso, tratamento especial através da Clínica Psicopedagógica. (p. 5)

Segundo o mesmo documento, a passagem do aluno da primeira fase para a segunda somente seria feita quando ele tivesse vencido o processo de alfabetização.

Entendeu-se que a eliminação de séries isoladas e a criação de fases contribuiria para a permanência do aluno em classes de alfabetização, isto é, para a continuidade do processo de alfabetização, de um ano para outro, quando ele não 
vencia as dificuldades básicas do processo de ler, eliminando-se a possibilidade de o aluno voltar à estaca zero, em uma outra série (Brasília, 1969, p. 4).

$\mathrm{O}$ aumento das matrículas nas escolas do DF impediu a continuidade da organização da escolaridade por meio de fases e etapas. Seu término deu-se no final da década de 60 . Na década de 80 foi implantado o Projeto ABC com a finalidade de as crianças desenvolverem todo o processo de alfabetização sem descontinuidade e sem vivenciarem fracasso. Muitas ações importantes foram implementadas, como formação de professores e criação de escolas que atuassem como centros de referência. Porém, o projeto teve o seu fim decretado. Na década de 90, mais precisamente de 1995 a 1998, ações semelhantes foram criadas, mas duraram pouco tempo.

\section{BLOCO INICIAL DE ALFABETIZAÇÃO - BIA}

A Secretaria de Estado de Educação do Distrito Federal iniciou a implantação do Ensino Fundamental de 9 anos em 2005, com a incorporação das crianças de 6 anos de idade. Para tanto, criou o Bloco Inicial de Alfabetização - BIA - em busca da tão sonhada qualidade de ensino para todos - em que mais do que todos na escola, pretende-se todos aprendendo na escola (Brasília, 2005, p. 4).

O documento que orienta a implantação do BIA é dirigido ao professor, afirmando o desejo da instituição de com ele abrir

um diálogo que suscite sua reflexão, bem como a incorporação dos pressupostos que regulam toda a estrutura do BIA, tomando como ponto de partida o seu saber, produzido no dia-a-dia de sua sala de aula, para que as posições assumidas possam ser identificadas com maior clareza. (op. cit., p 5)

O referido documento é apresentado como uma proposta cuja complementação será construída pelo coletivo da escola. Salienta-se a importância do comprometimento do professor e seu envolvimento na implantação do BIA, de modo que os alunos experimentem aprendizagem dinâmica, prazerosa e eficaz.

O Distrito Federal vem atendendo crianças de 6 anos de idade em suas escolas no $3^{\circ}$ período da Educação Infantil, de forma ainda não universalizada. Em 2005, iniciou-se a incorporação dessas crianças ao ensino fundamental, de modo que o atendimento esteja consolidado em toda a rede de ensino até 2008, conforme estabelece a Lei n. 3.483, de 25/11/04, DODF n. 225. A expectativa da Secretaria de Educação é que 
a escola, a partir das diretrizes e orientações emitidas pela Secretaria de Estado de Educação, possa elaborar sua própria proposta de trabalho, partilhando suas experiências com outras escolas do sistema de ensino, de tal forma que essas experiências venham enriquecer e agilizar a mudança, para que seja instalada em toda a Rede uma nova cultura escolar, sempre comprometida com o sucesso de todos os alunos. (op. cit., p.9)

O objetivo geral do BIA é reestruturar o Ensino Fundamental para 9 anos, garantindo à criança a aquisição da leitura/escrita/letramento, bem como o seu desenvolvimento integral. Os objetivos específicos referem-se à reorganização do tempo e dos espaços escolares, à reestruturação do processo de ensino-aprendizagem, à organização do currículo escolar, à sistematização do processo de alfabetização e à orientação da ação educativa do professor.

O BIA compreende o atendimento às crianças de 6,7 e 8 anos, enturmadas pelo critério de idade: 6 anos - etapa I; 7 anos - etapa II; 8 anos - etapa III

Nas primeiras semanas de aula é realizada a avaliação diagnóstica, para se conhecerem as habilidades e competências já adquiridas. Após esse período, os alunos são reagrupados. Afirma-se que essa avaliação não tem caráter classificatório.

O documento Orientações gerais para o ensino fundamental de 9 anos: Bloco Inicial de Alfabetização, de onde se retiraram as informações aqui expostas, apresenta-se como uma versão preliminar. Dois de seus componentes chamam a atenção: o trabalho coletivo dos professores e o projeto interventivo, que serão discutidos a seguir.

\section{TRABALHO COLETIVO DOS PROFESSORES}

Repetidas vezes, ressalta-se a necessidade de trabalho coletivo dos professores e das escolas. Isso pode ser interpretado, por um lado, como um aspecto positivo, pelo fato de não se entregar uma proposta inteiramente pronta às escolas, dando-lhes a possibilidade de organizarem seu trabalho. Contudo, por outro, pode-se entender que, com isso, a responsabilidade pelo sucesso ou fracasso está inteiramente dependente delas.

No item "Apresentação", o documento introduz a intenção de desenvolvimento de trabalho coletivo: discutir essas questões no interior da escola é de suma importância para que as dimensões imprescindíveis à totalidade do processo de alfabetização possam ser construídas no coletivo (op. cit., p. 5). 
No mesmo item e na mesma página, aponta-se a necessidade de uma grande discussão coletiva para que a construção de uma proposta curricular para o BIA possa incorporar a experiência dos professores, cujo produto detalharia as competências e habilidades para cada etapa do BIA.

A introdução do trabalho com ciclos modifica o equilíbrio entre responsabilidades individuais e coletivas, tornando necessários não somente o trabalho em equipe, mas, também, a cooperação de todos os profissionais que atuam na escola, com base em um projeto (Perrenoud, 2000a, p. 107). Na situação investigada, cada escola possui o seu projeto político-pedagógico e o projeto interventivo. Este último será analisado posteriormente.

Para o sucesso do projeto interventivo (atendimento aos alunos com mais de 8 anos de idade), afirma-se

que a escola deve envolver todos os professores da Educação Infantil e que atuam no Ensino Fundamental - BIA, bem como outros professores de outras séries que desejam conhecer e colaborar com esse projeto de reforço escolar, utilizando-se das horas de coordenação destinadas ao reforço escolar. É preciso lembrar que os alunos são do Ensino Fundamental de 9 anos e que o projeto é do estabelecimento de ensino e não somente dos professores do BIA. (op. cit., p. 15, grifos meus)

Observa-se que o documento insiste na idéia de que a escola se aproprie da organização e do desenvolvimento do trabalho do BIA. Com relação à avaliação, não se inclui o propósito de adoção de práticas participativas, inclusive com o envolvimento dos alunos.

No item destinado à avaliação, declara-se que

entender o BIA como um Bloco de Alfabetização exige que os profissionais que nele atuam desenvolvam um trabalho de equipe - planejem, executem seus planejamentos e avaliem todo o processo de ensino-aprendizagem de forma cooperativa, integrada e criativa. (op. cit., p. 40)

Ao tratar do reagrupamento de alunos, o documento, mais uma vez, menciona a necessidade do trabalho conjunto dos professores:

Todos os professores do estabelecimento de ensino que atuam na Educação Infantil e no Ensino Fundamental, no BIA, devem estar envolvidos no trabalho de reagrupamento, visto que o reagrupamento faz parte da metodologia do programa... (op. cit., p. 41) 
No item "Considerações finais" do documento, lê-se que

o sucesso do BIA está vinculado ao coletivo da escola pela condição de sua vontade, comprometimento e responsabilidade com suas crianças. É por isso que a Secretaria de Estado de Educação do Distrito Federal, ao elaborar esta orientação, optou por uma abordagem de natureza ampla, cabendo às escolas organizarem-se conforme suas especificidades. (op. cit., p. 43)

A afirmação acima é a mais contundente delas. Parece que a intenção é a de se entregar a responsabilidade pelo desenvolvimento do BIA às diretorias regionais de ensino e às escolas. Duas contribuições importantes têm sido recebidas pelas escolas: ações de formação continuada dos professores e criação dos Centros de Referência em Alfabetização.

As orientações fornecidas pelo documento parecem coincidir com uma das nove teses publicadas pelo Grupo de Pesquisa e Inovação que acompanha as escolas de ensino fundamental em Genebra, sobre a progressão na perspectiva dos ciclos (Perrenoud, (2000a, p. 53): a gestão da progressão dos alunos exige que a equipe docente assuma coletivamente a responsabilidade de toda decisão relativa ao percurso dos alunos, de acordo com a totalidade dos parceiros internos e externos à escola.

Embora o documento orientador insista na necessidade de desenvolvimento de trabalho coletivo nas escolas, não se menciona a participação das mesmas nas decisões para a implantação do BIA, incluídos os critérios para escolha da Diretoria Regional de Ensino de Ceilândia como a primeira a adotá-lo.

\section{PROJETO INTERVENTIVO: COM QUE MARGEM DE AUTONOMIA?}

Os alunos com idade acima de 8 anos são enturmados na etapa III. São formadas turmas específicas para o atendimento daqueles que, após a avaliação diagnóstica, não demonstrarem as habilidades necessárias para a sua enturmação na $3^{a}$ série.

Cada escola deve apresentar projeto de atendimento a esses alunos, incluindo as atividades que serão oferecidas no turno escolar e no turno contrário. Esse projeto deve ser de cunho interventivo a fim de buscar condições de efetivar a alfabetização desses alunos. (op. cit., p. 14)

Recomenda-se que todos os professores que atuam na educação infantil e no BIA se envolvam nesse projeto de reforço escolar, porque os 
alunos integram o ensino fundamental, e o projeto é da escola e não somente dos professores do BIA (op. cit., p. 15).

Após apresentar experiências de organização da escolaridade em ciclos em algumas localidades (Escola Cabana, em Belém; Escola Plural, em Belo Horizonte; Escola Candanga, no DF; Escola Cidadã, em Porto Alegre), Freitas (2004, p. 14) comenta que essas propostas adotam a avaliação emancipatória, conduzindo à redução de reprovação e a ações de recuperação e reforço da aprendizagem do aluno, além de permitir que o estudante se veja como sujeito de um processo que visa construir o seu conhecimento. A mesma situação ocorre agora no DF. O BIA foi introduzido com o objetivo de diminuir o fracasso escolar. Ceilândia possuía, em 2005, 19.191 alunos no BIA, sendo 5.175 na I Etapa, 7.354 na II Etapa e 6.662 na III Etapa. Desse total, 5.138 tinham idade acima de 8 anos (dados projetados em slide durante exposição da professora Eliana Ferrari em sessão solene na Câmara Legislativa do Distrito Federal, no dia 05/10/05).

Como uma das atividades da pesquisa que vem sendo conduzida, foram analisados 33 dos 52 projetos interventivos de escolas de Ceilândia. Os aspectos mais freqüentes nesses projetos são apresentados a seguir:

- Observaram-se dificuldades para elaboração do projeto, principalmente quanto aos itens que devem compô-lo e quanto ao seu conteúdo.

- Nenhum deles apresenta a situação em que os alunos se encontravam. Não se explicitam as necessidades específicas. Isso pode indicar que o trabalho continuará sendo desenvolvido de forma igual para todos. Se o projeto é interventivo, como o nome indica, espera-se que as atividades sejam diversificadas.

- As intervenções a serem realizadas são citadas de forma genérica. Por exemplo: serão ministradas aulas de reforço (em horário contrário ao turno normal). No seu conjunto, as ações apresentam-se de forma vaga e padronizada.

- A maioria não apresenta os recursos disponíveis para a execução do projeto. Três deles solicitam recursos adicionais, como mais salas de aula e encaminhamento de professores para atender aos alunos em outro turno.

- Uma escola expõe o contexto em que se insere o BIA: não há salas disponíveis para a realização de qualquer atividade mais elaborada com os alunos. Todos os espaços são ocupados. Atividades em horário contrário são realizadas precariamente, apesar de todos os esforços do grupo docente e da direção em atender bem a comunidade escolar. Por 
ser uma comunidade bastante carente, muitas são as dificuldades no que se refere ao aspecto pedagógico. Grande parte dos alunos não tem material escolar e isso dificulta o trabalho de sala de aula. A questão familiar também é um aspecto que, infelizmente, dificulta o trabalho escolar. Dos alunos que apresentam defasagem, poucos têm acompanhamento dos pais (a maioria não tem nenhum), muitos são filhos de pais separados ou têm um dos genitores preso ou foragido ou, ainda, moram com avós, tios, dentre outros. Com relação aos aspectos intra-escolares, devemos destacar o fato de nossa escola não ter espaço suficiente que nos possibilite fazer atividades psicomotoras e lúdicas. A área que nós temos é uma quadra de esportes, da comunidade, que fica nos arredores da escola e que não pode ser usada freqüentemente.

- O item avaliação, central no trabalho com blocos ou ciclos e, particularmente, em projetos interventivos, é o mais frágil de todos: em 10 projetos não é sequer mencionado; os que o incluem o fazem de forma bastante resumida, chegando a ser o menos desenvolvido; não se descreve a avaliação da aprendizagem dos alunos (procedimentos, momentos, sujeitos) e a do trabalho pedagógico do projeto.

- Vinte e três projetos incluem a avaliação da aprendizagem dos alunos, de forma vaga, como por exemplo: será feita ao longo do ano, através da observação contínua do desenvolvimento do aluno, redirecionando o trabalho pedagógico sempre que for necessário; através das atividades apresentadas pelos alunos; o aluno será avaliado ao longo do processo, observando seu desenvolvimento, interesse e participação; ocorrerá de maneira contínua, observando e respeitando os limites de cada aluno; além das avaliações normais da prática pedagógica, serão observados o interesse, a participação e a freqüência destes alunos, tanto nas atividades intraclasse quanto nas atividades extraclasse, durante todo o ano letivo.

- A maioria dos projetos não menciona a avaliação do projeto em si. Quando isso ocorre, é feito de maneira vaga: A avaliação do projeto em questão será feita semanalmente nas coordenações coletivas.

- Um dos projetos tem o nome "Começar de novo" e outro "Reaprender", o que poderá significar entendimento inadequado do seu propósito.

- Outro projeto apresenta como meta elevar o nível de alfabetização dos alunos fora da faixa etária em $80 \%$ até o final de 2005. E os outros $20 \%$ ? O que acontecerá com eles? 
- Os projetos, de modo geral, referem-se a alunos com problemas disciplinares e com dificuldades de aprendizagem e à deficiência do processo de ensino-aprendizagem. Um deles afirma ser seu objetivo sanar as dificuldades encontradas por esses alunos para que possam ser promovidos em tempo hábil. Estas afirmações revelam: a) o entendimento de que os alunos apresentam "dificuldades de aprendizagem" e não "necessidades"; b) compromisso com a aprovação e não com a aprendizagem.

A análise dos projetos indica duas grandes necessidades. A primeira requer que a escola tenha clareza dos propósitos do projeto interventivo. Ele é provisório. As necessidades de aprendizagem manifestadas pelos alunos devem ser atendidas, assim que surgirem. Os alunos participantes do projeto não constituem turmas fixas. Os grupos são reconstituídos constantemente, levando-se em conta as necessidades que vão surgindo. Isso significa usar os tempos e espaços escolares de forma dinâmica, em busca da aprendizagem.

A segunda necessidade, decorrente da primeira, é a de se vincular o projeto interventivo à avaliação formativa. Os alunos o integram por algum tempo para aprender e não para alcançar nota para "passar de ano". Além disso, o projeto tem caráter positivo e encorajador. Os alunos não podem se sentir humilhados nem constrangidos. Esse tipo de trabalho se insere em cultura avaliativa condizente com a avaliação formativa, de modo que professores e dirigentes educacionais usem informações sobre $o$ desempenho dos alunos para gerar novos conhecimentos o que tem dado bons resultados; partilhem as descobertas com colegas e construam sua capacidade de atender as necessidades de aprendizagem dos alunos. Cultura de avaliação é a adoção de linguagem comum sobre os objetivos da aprendizagem e do ensino, assim como a compreensão comum dos propósitos da avaliação para atingir esses objetivos (OECD, 2005, p. 25).

Em questionário aplicado a 147 professores do BIA, de diferentes escolas, em dezembro de 2005, obtiveram-se as seguintes informações: $63,2 \%$ afirmaram não ter participado da elaboração do projeto interventivo, porque ele não foi elaborado em suas escolas; 2,04\% declararam não ter participado da elaboração; 34,6\% disseram ter participado da elaboração. Estes últimos apontaram as seguintes dificuldades para a elaboração: resistência dos professores (a mais apontada), falta de espaço físico para realização das atividades com alunos, falta de comprometimento dos professores, falta de consenso entre os professores, falta de material didático, falta de coordenador pedagógico na escola e número excessivo de alunos nas turmas. 
Para que se pratique a autonomia que o trabalho coletivo requer, as necessidades e as dificuldades encontradas precisam ser discutidas pelas equipes das escolas, com o apoio de referencial teórico, e condições mínimas, para o desenvolvimento do trabalho, devem ser oferecidas.

\section{A AVALIAÇÃO NO BIA}

Segundo o documento orientador do BIA, há o propósito de que a avaliação ocorra de forma sistemática, diagnóstica, processual, contínua, cumulativa e participativa, para que os professores possam tomar decisões relativas à regulação do processo (Brasília, 2005, p. 40).

Além disso, pretende-se que ela supere a visão estática e classificatória e chegue a ser formativa. Com base nos resultados da avaliação são feitos os agrupamentos de alunos com necessidades específicas de aprendizagem, os quais devem ser dinâmicos, temporários e rotativos, de modo que garantam a sua reinserção nas atividades cotidianas de seu grupo de origem (op. cit., p. 41). Cabe ao professor estabelecer critérios intencionais de agrupamentos e reagrupamentos dos alunos, levando em conta aspectos cognitivos e afetivos da aprendizagem.

Como exigências para o desenvolvimento do processo avaliativo pretendido, incluem-se a atualização do professor quanto ao desenvolvimento infantil e o deslocamento do eixo do mero controle do processo de ensino-aprendizagem para um acompanhamento inserido numa abordagem mais sistêmica - planejamento, gestão e aprendizado da prática docente (op. cit., p, 43). Nessa perspectiva, acrescenta-se, os erros e as dúvidas são vistos, numa nova ótica de avaliação, como episódios altamente significativos para a ação educativa, gerando novas oportunidades de conhecimento.

A avaliação é entendida como excelente material de análise para o educador, pois revela como o educando está pensando, possibilitando ajudá-lo a reorientar a construção do conhecimento. Considera-se a necessidade de avaliação do trabalho realizado durante o ano e do registro de toda a caminhada por meio de diversos instrumentos: portfólios, registros diários e individuais, caderno de observação do professor. Nesta parte do documento, apresenta-se a avaliação da aprendizagem do aluno. Não se recomenda a avaliação do trabalho pedagógico, realizado com os diferentes grupos de alunos, nas diferentes atividades, nem a avaliação do trabalho do BIA sob a responsabilidade de cada escola: apenas o aluno é alvo da avaliação. Essa ainda é uma das fragilidades da concepção e da prática avaliativa. 
Percebe-se a intenção de rejeitar práticas avaliativas classificatórias e de adotar a avaliação formativa. Contudo, esse é um longo e árduo caminho a ser percorrido, porque, ao que tudo indica, todos os educadores que atuam no BIA já tiveram mais contato com a avaliação classificatória do que com a formativa. A continuidade do processo de formação continuada desses educadores é de fundamental importância para o sucesso do BIA.

\section{DESAFIOS PARA A AVALIAÇÃO}

Vários aspectos justificam a necessidade de se apontarem os desafios que a organização da escolaridade em ciclos ou em blocos, como é o caso do DF, coloca para a avaliação. Dentre eles, citam-se: 1) as escolas públicas do DF já passaram por três experiências de organização do seu trabalho em ciclos ou etapas. O BIA é a quarta delas. Talvez, em todas elas a avaliação não tenha cumprido bem o seu papel, pelo fato de terem durado pouco e de não terem sido registrados os resultados do trabalho. Nem sempre se registram devidamente esses resultados, o que pode demonstrar incompreensão dos objetivos da avaliação; 2) a avaliação é central no trabalho com ciclos. Articulada aos objetivos do trabalho, com eles forma o par que norteia o seu desenvolvimento; 3) a expressiva produção sobre avaliação, no Brasil, contribui para a compreensão do papel dessa categoria na organização do trabalho escolar. Os aspectos acima citados, em seu conjunto, conduzem à formulação dos desafios que se seguem.

PRIMEIRO DESAFIO - implantar bloco de alfabetização ou ciclos implica construir uma escola desvinculada das características da escola seriada, como a fragmentação do trabalho e o seu desenvolvimento nãodiferenciado, e a avaliação centrada em notas, em aprovação e em reprovação. Já o trabalho escolar organizado em ciclos tem por objetivo usar os tempos e espaços da escola de forma dinâmica e não padronizada, de modo que se atendam às necessidades e aos interesses que vão sendo manifestados. Isso requer a construção da proposta pedagógica pela própria escola ao longo do ano, com a participação de professores, alunos e pais. O eixo orientador desse trabalho é a aprendizagem dos alunos, o que provoca a necessidade de se promover, também, a aprendizagem dos professores e o desenvolvimento da escola.

Freitas (2004, p. 11) entende que

os ciclos propõem alterar os tempos e os espaços da escola de maneira mais global, procurando ter uma visão crítica das finalidades educacionais da escola. Está em 
jogo mais do que simplesmente liberar fluxos, ou sair-se bem nas avaliações de sistema ou, ainda, tirar a avaliação formal juntando séries em planejamentos plurianuais.

Nesse sentido, outra lógica de avaliação é requerida: não mais a classificatória, episódica, punitiva e seletiva, mas a que apóie a aprendizagem. Notas, aprovação e reprovação, a recuperação nos moldes tradicionais, turmas caminhando juntas durante todo o ano letivo, responsabilização dos alunos e de suas famílias pelo fracasso escolar e pela falta de autonomia das escolas para organizarem seu trabalho são práticas que deixam de existir. Por isso outra organização do trabalho escolar precisa ser encontrada pelos gestores dos sistemas de ensino e pelas equipes que atuam nas escolas. Agrupar séries para a constituição de ciclos ou blocos não muda nada. O compromisso com a aprendizagem de todos os alunos, em todas as dimensões, é o norteador do trabalho.

Os agrupamentos e reagrupamentos são dinâmicos e constantes. Não existem turmas fixas, que caminham juntas durante todo o ano letivo. Essa organização "disciplinada" do trabalho escolar só serve às atividades burocráticas da escola. As conquistas dos alunos é que regem a forma de agrupá-los e reagrupá-los.

Portanto, um dos grandes desafios é a construção, pela equipe da escola, de processo que possibilite a realização diária da avaliação da aprendizagem do aluno, por meio de todas as atividades desenvolvidas. Em lugar de se adotarem procedimentos avaliativos com data e hora marcadas e conteúdos definidos, analisam-se e avaliam-se todas as atividades realizadas, por meio de diferentes linguagens. Essas são as que revelam verdadeiramente o seu progresso.

Nos projetos interventivos analisados, não se pôde perceber essa concepção de avaliação. O que o documento orientador preconiza não está sendo praticado. Prevaleceu o que ainda constitui prática comum: o processo avaliativo não é planejado; costuma acontecer de maneira intuitiva e espontânea, porque o professor vai formulando, durante a interação com os alunos, sua compreensão acerca do seu desenvolvimento. Nem sempre são feitos registros desses juízos.

Como o item avaliação foi brevemente abordado nos projetos, não se sabe se o princípio do trabalho coletivo é adotado também para a avaliação. Apenas um projeto mencionou, ligeiramente, a discussão das suas atividades pelo conjunto dos professores.

É importante ressaltar que nos projetos interventivos a avaliação merece atenção especial, pois os alunos por eles atendidos são os que enfrentam maiores necessidades. Com esses alunos tudo deve ser muito bem organizado para que nenhum se perca. 
SEGUNDO DESAFIO - o entendimento de que enquanto se avalia se aprende e enquanto se aprende se avalia completa o desafio anterior. Nesse contexto, não só o professor avalia e nem só o aluno aprende. Ambos aprendem e avaliam. O professor observa, identifica e analisa as conquistas de cada aluno para orientar a continuidade da sua aprendizagem e a do trabalho pedagógico. Esse processo o ensina a encontrar as maneiras mais adequadas de desenvolver o trabalho e de avaliá-lo. É a avaliação formativa em ação. Perrenoud (2000a, p. 51) entende que a avaliação formativa inscreve-se na relação diária entre o professor e seus alunos, e seu objetivo é auxiliar cada um a aprender, não a prestar contas a terceiros. Essa é a essência da avaliação formativa: o professor analisa o trabalho do aluno freqüentemente, enquanto ele ocorre, para fazer as intervenções no momento necessário. Além disso, registra as informações que coleta para construir o retrato da turma. Nada fica para depois, para um possível balanço. Muda-se a postura do professor diante da avaliação e da aprendizagem. Seu papel não é o de elaborar e corrigir provas, atribuir-lhes notas e separar os alunos segundo rótulos classificatórios, de modo que as ações sejam desenvolvidas mais tarde. Fernandes (2003, p. 136) argumenta que o trabalho com ciclos pressupõe prática avaliativa formativa, não cabendo falar em aprovação e, sim, em promoção (entendida como promoção da aprendizagem).

A intenção do documento orientador do BIA é a de adoção da avaliação formativa. Esse é também o entendimento de Perrenoud (2000, p. 113), para quem dificilmente se pode imaginar balanços sendo feitos apenas no final do ciclo, o que excluiria qualquer regulação contínua.

Contudo, essa avaliação somente alcançará propósitos formativos se o processo for construído pelos professores, em cada escola. O que faz a avaliação ser formativa não é a intenção dos gestores, mas a prática dos professores.

TERCEIRO DESAFIO - avaliação é processo; não é sinônimo de procedimento ou instrumento. É comum lermos em provas: "avaliação de matemática", "avaliação de história", como se elas representassem sozinhas todo o processo. Sendo amplo, o processo avaliativo é planejado, resultando em um plano em que constem: seus objetivos, seus componentes, seus participantes, as modalidades de avaliação (formal e informal), os procedimentos de avaliação, o uso dos resultados obtidos.

Como processo, a avaliação também é avaliada, para que se analise se está cumprindo o que dela é esperado.

QUARTO DESAFIO - a organização da escolaridade em ciclos, particularmente em blocos de alfabetização, utiliza a avaliação informal com intenção inclusiva. Tem sido entendido que o trabalho com ciclos não 
adota a avaliação formal, pois esta, geralmente, é feita somente por meio de provas que costumam ser acompanhadas de notas. É um equívoco, porque a avaliação formal pode ser feita de forma ampla, usando vários procedimentos e abrangendo diferentes linguagens. Todas as atividades realizadas pelos alunos incluem-se na avaliação formal. Acontece que, nos anos iniciais da educação fundamental, o professor tem contato duradouro com seus alunos, possibilitando que ele conheça melhor cada um deles: suas necessidades, seus interesses, suas capacidades. Por meio dessa interação é que se realiza a avaliação informal. Assim, corre-se o risco de prevalecerem os aspectos perversos da avaliação informal, provocando a exclusão de alunos, conforme alerta Freitas (2004, p. 21). O mesmo autor aponta a necessidade de se evitarem duas situações: 1) a troca da avaliação formal pela valorização da informal de caráter hierarquizador e excludente; 2) a criação de trilhas diferenciadas de progressão no interior da escola (exclusão por dentro). Os projetos interventivos, se não forem conduzidos adequadamente, poderão significar uma dessas trilhas. Por isso, a inclusão dos alunos nesses projetos deve ser rápida, para que não adquiram rótulos.

Segundo dados do Saeb 2003 (Inep..., 2004), 13\% dos alunos da $4^{\text {a }}$ série afirmam se sentir "deixados de lado" na sua turma. Para 34\%, essa situação ocorre de vez em quando. Percebe-se, então, que $47 \%$ desses alunos se sentem rejeitados. Essa rejeição, seja pelos colegas ou pelos professores, pode resultar da avaliação informal e ser um dos elementos causadores da internalização da exclusão, isto é, os excluídos da escola continuam em seu interior. Bourdieu e Champagne (1998, p. 222) dão a esse fato o nome de exclusão branda, por retratar práticas insensíveis, no duplo sentido de contínuas, graduais e imperceptíveis, despercebidas, tanto por aqueles que as exercem como por aqueles que são suas vítimas.

A avaliação informal pode servir tanto a propósitos positivos quanto a negativos, por meio do encorajamento, no primeiro caso, e do desencorajamento, no segundo. Tanto a avaliação formal quanto a informal são importantes, devendo ser empregadas no momento certo e de maneira adequada. A avaliação formal é insuficiente para abranger todos os estilos de aprendizagem. A informal pode complementá-la (Villas Boas, 2004, p. 29).

Tratando da avaliação informal, Freitas (2002, p. 315) comenta que

Professores e alunos defrontam-se na sala de aula, construindo representações uns dos outros. Tais representações e juízos orientam novas percepções, traçam possibilidades, estimam desenlaces, abrem ou fecham portas e, do lado do professor, afetam o próprio envolvimento deste com os alunos, terminando por interferir positiva ou negativamente com as estratégias de ensino postas em marcha na sala de aula. É aqui que se joga o sucesso ou o fracasso do aluno - nesse plano informal 
e não no plano formal. De fato, quando o aluno é reprovado pela nota, no plano formal, ele já tinha sido, antes, reprovado no plano informal, no nível dos juizos de valor e das representações do professor - durante o próprio processo.

QUINTO DESAFIO - a formação dos professores e demais educadores, para a adoção da avaliação formativa, é imprescindível para o enfrentamento dos desafios anteriores. Os professores aprendem a avaliar enquanto se formam. Esse processo é longo: abrange toda a sua trajetória escolar como alunos, desde a educação infantil até a universidade. Tem continuidade a partir do momento em que começam a atuar como professores e, às vezes, se desenvolve em cursos especialmente destinados à sua formação. Todas as situações que presenciam e vivenciam como alunos, nos vários níveis do processo de escolarização, fazem parte da sua constituição de professores e podem ser bem marcantes. Por ser um tema que tem merecido pouca atenção nos cursos de formação, em nível médio e superior, pressupõe-se que os atuais professores estejam reproduzindo as práticas dos seus ex-mestres. E essas práticas nem sempre se inserem na avaliação formativa. Perrenoud (1999, p. 16) alerta que a formação dos professores trata pouco de avaliação e menos ainda de avaliação formativa.

A não-inserção da avaliação em 10 projetos interventivos e a sua inserção incompleta nos outros 23 indicam que esse tema precisa fazer parte da formação continuada dos professores e dos demais educadores. Não é comum encontrar diretores, orientadores educacionais e coordenadores pedagógicos debatendo juntamente com professores a teoria e a prática avaliativa. Pensa-se que avaliar é tarefa exclusiva de professores. Enquanto assim concebermos a avaliação, pouco ou nada avançaremos rumo às práticas formativas.

O tema avaliação não foi objeto de análise nos encontros de formação continuada dos professores do BIA, de Ceilândia, ocorridos semanalmente, durante o ano de 2005.

SEXTO DESAFIO - a prática da avaliação formativa requer adoção de políticas educacionais que ofereçam as condições do trabalho pedagógico que alunos e professores merecem. Essa avaliação é coerente com o trabalho pedagógico que luta contra o fracasso e as desigualdades, como quer a organização da escolaridade em ciclos ou blocos. Porém, encontra obstáculos advindos de políticas indecisas, e outros de ordens diversas: programas sobrecarregados, atividades que não privilegiam a diferenciação, tempos escolares compartimentados, turmas numerosas, espaços escolares impróprios; insuficiência ou excessiva complexidade dos modelos de avaliação formativa propostos aos professores etc. (Perrenoud, 1999, p. 16). 


\section{REFERÊNCIAS BIBLIOGRÁFICAS}

BOURDIEU, P.; CHAMPAGNE, P. Os Excluídos do interior. In: NOGUEIRA, Maria Alice; CATANI, Afrânio (orgs.) Escritos de educação. Petrópolis: Vozes, 1998.

BRASÍLIA, DF. Conselho de Educação. Boletim n. 1. Brasília, 1966.

Secretaria de Educação e Cultura. Coordenação de Educação Primária. Ensino Primário no Distrito Federal. Brasília, 1969.

Secretaria de Estado de Educação. Subsecretaria de Educação Pública. Orientações gerais para o ensino fundamental de 9 anos: Bloco Inicial de Alfabetização. Brasília, 2005.

ENGUITA, Mariano F. A Face oculta da escola: educação e trabalho no capitalismo. Porto Alegre: Artes Médicas, 1989.

FERNANDES, Cláudia de Oliveira. A Escolaridade em ciclos: práticas que conformam a escola dentro de uma nova lógica - a transição para a escola do século XXI. Rio de Janeiro, 2003. Tese (dout.) Pontifícia Universidade Católica do Rio de Janeiro. 353 p.

FREITAS, Luiz Carlos de. A Internalização da exclusão. Educação $\mathcal{E}$ Sociedade, Campinas, v. 23, n. 80, p. 301-327, set./2002.

Ciclos ou séries? O que muda quando se altera a forma de organizar os tempos-espaços da escola? Caxambu, 2004. [Apresentado em: REUNIÃO ANUAL DA ANPEd, 27] 33 p.

INEP traça perfil do aluno no estágio muito crítico de aprendizagem. 14/09/2004. Disponível em: www.inep.gov.br/imprensa/noticias/saeb/ news04_17_imp.htm.

OECD. Formative assessment: improving learning in secondary classrooms. Paris: OECD Publishing, 2005.

PERRENOUD, Philippe. Avaliação: da excelência à regulação das aprendizagens - entre duas lógicas. Porto Alegre: Artes Médicas, 1999.

ArtMed, 2000.

Pedagogia diferenciada: das intenções à ação. Porto Alegre: 
PERRENOUD, Philippe. Dez novas competências para ensinar. Porto Alegre: ArtMed, 2000a.

VILLAS BOAS, Benigna M. de Freitas. Portfólio, avaliação e trabalho pedagógico. Campinas, SP: Papirus, 2004.

Recebido em: outubro 2006

Aprovado para publicação em: março 2007 
